\title{
Preparation and Performance of Gallium Nitride Powders with Preferred Orientation
}

\author{
Liping Kang ${ }^{1}$, Lingli Wang ${ }^{1}$, Haiyan Wang ${ }^{1 *}$, Xiaodong Zhang ${ }^{1}$, Yongqiang Wang ${ }^{1}$
}

${ }^{1}$ School of Physics and Electronic Engineering, Zhengzhou University of Light Industry, Zhengzhou City, Henan province, PR China, 450002

\begin{abstract}
The paper prepared the III-V semiconductor, hexagonal wurtzite Gallium nitride powders by calcining a gallium oxide in flowing ammonia above $900{ }^{\circ} \mathrm{C}(1173 \mathrm{~K})$. Because of the solid-state reaction process that the gallium oxide transformed to $\mathrm{GaN}$ through solid-state gallium oxynitrides $\left(\mathrm{GaO}_{\mathrm{x}} \mathrm{N}_{\mathrm{y}}\right)$ as inter-mediates, the Gallium nitride powders which are agglomerates of tens nanometers flake crystallites retain the rod shape and grain size of raw gallium oxide and have slight (002) plane preferred orientation. The near-edge emission of Gallium nitride at $346 \mathrm{~nm}$ has a blue shift of $187 \mathrm{meV}$ attributed to a decrease in disorder of the material that is decided by the (002) plane preferred orientation. The preferred orientation and a blue shift have some kind of reference significance to single crystal growth.
\end{abstract}

\section{Introduction}

As a representative of the third generation of semiconductor, Gallium nitride $(\mathrm{GaN})$ has a wide direct gap of $3.39 \mathrm{eV}$ at room temperature, high luminescent efficiency and low temperature-quenching effect, promising application prospects in blue and UV lighting, Ultraviolet Detecting and other areas. Sapphire, Silicon chip and SiC are all the widely used substrates for the thin-film growth of GaN. However, there exists severe mismatch both in lattice parameters and thermal expansion coefficients between $\mathrm{GaN}$ and the substrates, which introduce stresses in the first few layers of the grown GaN. Therefore the development of high-purity GaN crystalline for homoepitaxy by wafers is a trend in the future.

The most popular methods to grow single-crystal bulk GaN demand high purity and single phase $\mathrm{GaN}$ powder as precursor source, thus one of current significance research topic is the synthesis $\mathrm{GaN}$ powder directly. In this research, we took an easy method to synthesize GaN powders, which is based on the reduction reaction of gallium oxides $\left(\mathrm{Ga}_{2} \mathrm{O}_{3}\right)$ in ammonia gas.

\footnotetext{
*Corresponding author: wanghaiyan@zzuli.edu.cn, 2005012@zzuli.edu.cn
} 


\section{Experiments}

The starting materials include $\beta-\mathrm{Ga}_{2} \mathrm{O}_{3}(99.999 \%)$ and liquid ammonia $\left(\mathrm{NH}_{3}, 99.999 \%\right)$. $0.25 \mathrm{~g} \mathrm{Ga}_{2} \mathrm{O}_{3}$ powders were placed in a quartz tube which was fixed in a furnace. After the air in the tube was expelled by argon (Ar, 99.999\%) gas flow for 5 minutes, the furnace was heated to $600{ }^{\circ} \mathrm{C}$ at the rate of $10^{\circ} \mathrm{C} / \mathrm{min}$ with an Ar flow. Then the flow was changed into $\mathrm{NH} 3$ mixing in $\mathrm{Ar}\left(\mathrm{NH}_{3} / \mathrm{Ar}, \mathrm{NH}_{3}: \mathrm{Ar}=1: 2\right)$ and the temperature was increased continuously with a rate of $5{ }^{\circ} \mathrm{C} / \mathrm{min}(\mathrm{K} / \mathrm{min})$ until it reached the reaction temperatures of $850{ }^{\circ} \mathrm{C}(1123$ $\mathrm{K}), 875{ }^{\circ} \mathrm{C}(1148 \mathrm{~K}), 900{ }^{\circ} \mathrm{C} \quad(1173 \mathrm{~K})$ and $925{ }^{\circ} \mathrm{C},(1198 \mathrm{~K})$ respectively. The reaction time under high-temperature condition was 30 minutes. In the cooling process, the $\mathrm{NH}_{3} / \mathrm{Ar}$ flow were kept until the temperature reached $600{ }^{\circ} \mathrm{C}(873 \mathrm{~K})$ and then it was switched to a pure Ar flow.

The as-synthesized GaN samples were characterized by powder X-ray diffraction (XRD) using a Bruker D8 Advanced X-ray diffract-meter with $\mathrm{Cu} \mathrm{K} \alpha$ radiation operating at $60 \mathrm{kV}$ and $80 \mathrm{~mA}$. The morphologies of the powders were investigated by JSM-6490LV scanning electron microscope (SEM). The high-resolution transmission electron microscope (HRTEM) lattice images and the corresponding selected-area electron diffraction (SAED) of an individual grain were from JEM-2100 (UHR) HRTEM. The luminous property of GaN was performed by a Horiba FL3 photoluminescence (PL) spectroscopy.

\section{Results and discussion}

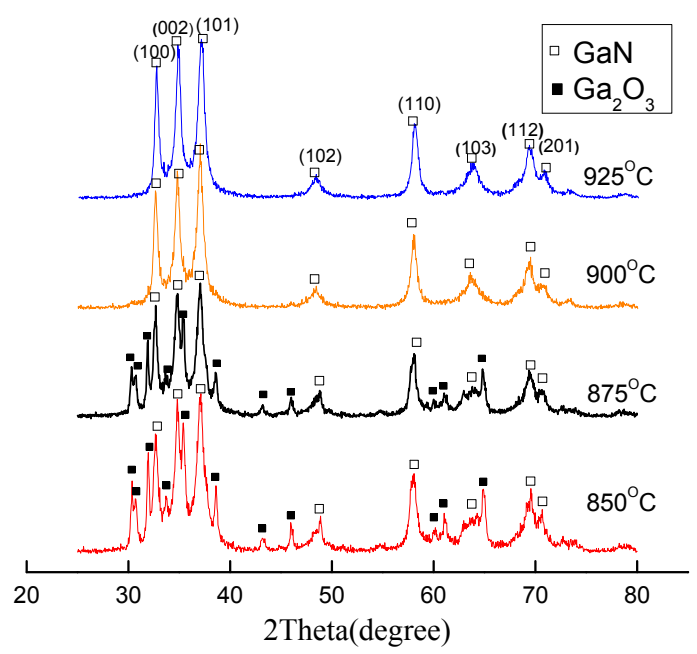

Fig. 1. X-ray diffraction patterns of $\mathrm{GaN}$ powders synthesized at different temperatures.

\subsection{Structure}

Fig. 1 shows the XRD patterns of GaN powder obtained at different temperatures. The XRD patterns show that the samples synthesized at $850{ }^{\circ} \mathrm{C}$ and $875{ }^{\circ} \mathrm{C}$ are mixtures of hexagonal wurtzite $\mathrm{GaN}$ and monoclinic $\beta-\mathrm{Ga}_{2} \mathrm{O}_{3}$ (PDF card no. 43-1012 with lattice constants of $\mathrm{a}=1.223 \mathrm{~nm}, \mathrm{~b}=0.304 \mathrm{~nm}, \mathrm{c}=0.58 \mathrm{~nm}$ and angles of $90,103.7,90$ degrees respectively). However, the $\mathrm{GaN}$ powders obtained at $900{ }^{\circ} \mathrm{C}$ and $925{ }^{\circ} \mathrm{C}$ have the typical wurtzite structure. According to PDF card no. 65-3410, the main peaks of the wurtzite structured GaN are indexed to refined lattice constants of $\mathrm{a}=0.3173 \mathrm{~nm}$ and $\mathrm{c}=0.5158 \mathrm{~nm}$. 
Even though no other diffraction peak were observed, it was possible that oxygen element existed in $\mathrm{GaN}$ samples grown at 900 degree and above because the starting materials were oxides. At the same time, an uncommon phenomenon is seen in the XRD patterns that the diffraction from (002) plans is extra strong compared with the other peaks. This result indicates that the present samples exist preferred (002) crystal plane orientation, like in the thin films [1].

After removing background of curves and fitting peaks processes, the average size of the sub-grains is rough calculated by the full width at half maximum using the Scherrer formula $(t=\lambda / B \cos \theta)$, as shown in Table 1 ; the number in parenthesis is error range. The sizes of $\mathrm{GaN}$ crystallite only from $\mathrm{GaN}$ diffraction peaks increase with synthesize temperature. The average sizes of powders obtained at $850{ }^{\circ} \mathrm{C}$ and $875{ }^{\circ} \mathrm{C}$ from the whole spectra are very large because the two samples are mixtures of $\mathrm{GaN}$ and large size $\mathrm{Ga}_{2} \mathrm{O}_{3}$ particles.

Table 1. The crystallite size of samples obtained at different temperatures

\begin{tabular}{lllll}
\hline Nitride temperature [degree] & 850 & 875 & 900 & 925 \\
\hline Average size of powder samples [nm] & $310(12)$ & $275(21)$ & $118(2)$ & $126(2)$ \\
\hline Average size of GaN crystallite [nm] & $69(4)$ & $118(3)$ & $118(2)$ & $126(2)$ \\
\hline
\end{tabular}

\subsection{Morphology}
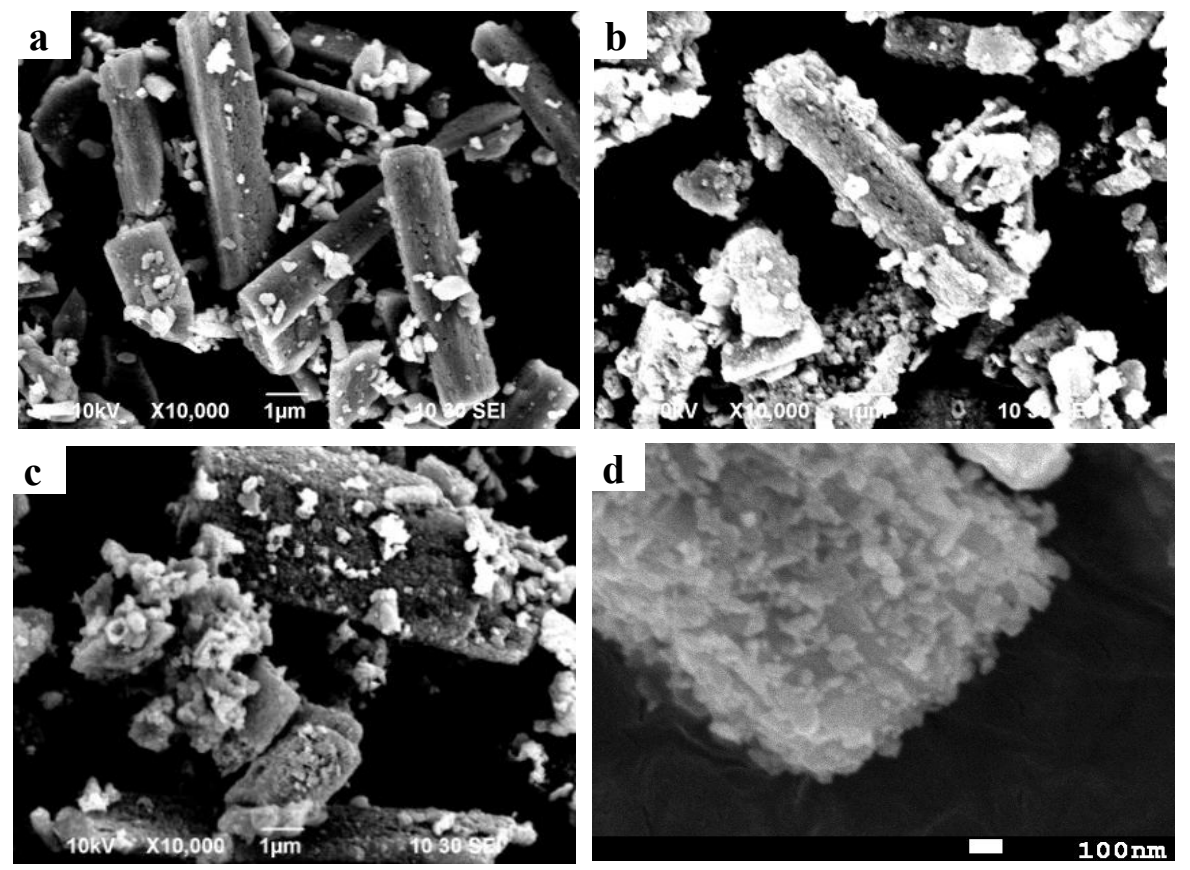

Fig. 2. SEM pictures of $\mathrm{Ga}_{2} \mathrm{O}_{3}$ (a), $\mathrm{GaN}$ samples annealed at $900{ }^{\circ} \mathrm{C}\left(\mathrm{b}\right.$ and d), at $875{ }^{\circ} \mathrm{C}$ (c).

SEM images of raw material $\mathrm{Ga}_{2} \mathrm{O}_{3}$ and $\mathrm{GaN}$ powders obtained at $900{ }^{\circ} \mathrm{C}$ and $875{ }^{\circ} \mathrm{C}$ are shown in Fig.2 (a), (b) and (c), respectively. The magnification times are all 10,000. The distribution of the powder size is wide spread from tens of nanometers to several 
micrometers. GaN samples grown at $900{ }^{\circ} \mathrm{C}$ and $875{ }^{\circ} \mathrm{C}$ were of rod morphology with a small quantity of $\mathrm{GaN}$ nanograins enclosed on its surface. The micrometer rod is consisting of particles about 100 nanometer, as show in Fig. 3 (d) $\mathrm{GaN}$ at $900{ }^{\circ} \mathrm{C}$ details image. The estimated average size is in a good agreement with calculated numbers of XRD. By the comparison of $\mathrm{Ga}_{2} \mathrm{O}_{3}$ and $\mathrm{GaN}$, we see that both of the shape and size of $\mathrm{GaN}$ powders are similar to those of raw material of $\mathrm{Ga}_{2} \mathrm{O}_{3}$. From this result it can be proved that the $\mathrm{GaN}$ powders retain the rod shape and grain size of $\mathrm{Ga}_{2} \mathrm{O}_{3}$. Thus, a conclusion of the conversion of gallium oxide to $\mathrm{GaN}$ don't go through the gaseous species of $\mathrm{Ga}_{2} \mathrm{O}$ but solid-state gallium oxynitrides $\left(\mathrm{GaO}_{\mathrm{x}} \mathrm{N}_{\mathrm{y}}\right)$ as inter-mediates is obtained [2]

TEM image, HRTEM image and selected area electron diffraction (SAED) pattern (inset) of the GaN powders at $925^{\circ} \mathrm{C}$ are shown in Fig. 3(a) and (b). TEM image shows the presence of irregular agglomerates of tens nanometers of tabular GaN crystallites, being consistent with the calculated results of table 1 . The d-spacing between the two adjacent lattice fringes is $0.2586 \mathrm{~nm}$ from (002) plane. The calibrated SAED pattern was depicted in the Fig. 2(c). Comparing to those of standard GaN powders and their d-spacing, all the diffraction rings could be attributed to hexagonal wurtzite GaN. The discontinuous diffraction rings demonstrate that the samples exists preferred orientation; this result keeps in line with our XRD measurement.
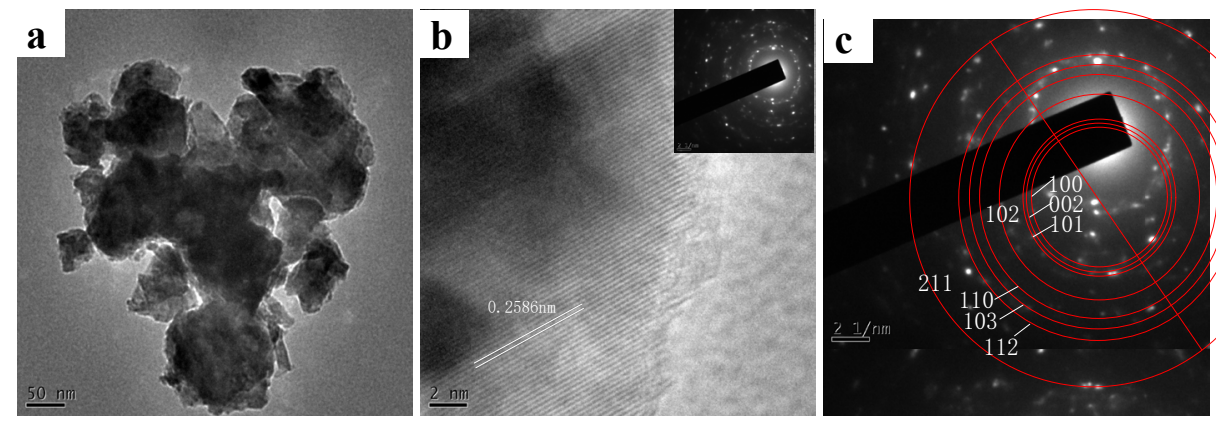

Fig. 3. TEM image (a), HRTEM image (b) and SAED pattern (c) of GaN at $925^{\circ} \mathrm{C}$.

Basing on anionic coordination polyhedron growth units theory model [3], the strong polarity faces grow faster and appear in smaller areas, whereas the weak polarity faces grow slower and appear in large areas [4]. In hexagonal wurtzite $\mathrm{GaN}$, the tetrahedron $\left[\mathrm{Ga}-\mathrm{N}_{4}\right]^{8-}$ growing from $\mathrm{GaO}_{4}$ tetrahedral is considered as the basic unit. Because the vertexes of $\left[\mathrm{Ga}-\mathrm{N}_{4}\right]^{8-}$ appear on the (110) faces,the (110) faces show higher surface energy and stronger polarity. On the contrary, the planes of $\left[\mathrm{Ga}-\mathrm{N}_{4}\right]^{8-}$ are parallel to $(002)$ faces, so the (002) faces of GaN particles have low surface energy and weak polarity. Therefore $(002)$ faces appear in large areas in the GaN particles growing process. As mentioned earlier, gallium oxide transforms to $\mathrm{GaN}$ via gallium oxynitrides $\left(\mathrm{GaO}_{\mathrm{x}} \mathrm{N}_{\mathrm{y}}\right)$ as inter-mediates. As the nitridation proceeds, the oxygen content in the intermediates gradually decreases, leading to complete conversion to $\mathrm{GaN}$ and this conversion completed from outside to inside of the rod gradually. The before-mentioned factors result in that there are some $\mathrm{GaN}$ plates which are corresponding to the (002) plane attaching on the rod surface. Therefore, the GaN materials obtained have slight (002) plane preferred orientation.

\subsection{Luminescence}

The luminescent properties of the $\mathrm{GaN}$ powders synthesized at $925^{\circ} \mathrm{C}, 900{ }^{\circ} \mathrm{C}$ and $875{ }^{\circ} \mathrm{C}$ were examined by photoluminescence (PL) spectroscopy at room temperature, and the $\mathrm{PL}$ spectra are shown in Fig. 4a. The exciting source is $294 \mathrm{~nm} \mathrm{UV.}$ 
The dominant emission of the obtained GaN powders is a broad emission from $320 \mathrm{~nm}$ to $400 \mathrm{~nm}$ centered near $360 \mathrm{~nm}$. This broad UV emission band of the GaN powders sample synthesized at $925{ }^{\circ} \mathrm{C}$ is fitted with four Gaussians and the peaks are located at $346 \mathrm{~nm}$ (3.584 eV), $364 \mathrm{~nm}(3.407 \mathrm{eV}), 365 \mathrm{~nm}(3.397 \mathrm{eV})$ and $398 \mathrm{~nm}(3.116 \mathrm{eV})$, as shown in the Fig. 4b. The raw date (red hollow square symbols), separated peaks (blue solid line) and the fitted curve (black dotted line) are all provided. The curve fitting result of the GaN powders sample synthesized at $900{ }^{\circ} \mathrm{C}$ is similar to that of the $\mathrm{GaN}$ powders sample synthesized at $925{ }^{\circ} \mathrm{C}$ within the margin of error, and the graph isn't given there.

The emission peak at $346 \mathrm{~nm}$ is considered belongs to a blue shift of the near band edge emission at $365 \mathrm{~nm}$ (3.39 eV) of the bulk GaN. The blue shift of $19 \mathrm{~nm}(187 \mathrm{meV})$ is attributed to a decrease on disorder of the material that is decided by the (002) plane preferred orientation. Considering the separation of the peaks is $174 \mathrm{meV}$ and $10 \mathrm{meV}$, the $364 \mathrm{~nm}$ and $365 \mathrm{~nm}$ peaks are possible the electron transition radiation between the shallow donor levels and the valence band [5]. The donor is believed to be a residual oxygen impurity from raw material [5]. The broad violet band centered at $398 \mathrm{~nm}$ is relating to defect levels. The well-known yellow band emissions from Carbon impurity deep acceptor defect energy are not observed.

However, the curve of the $\mathrm{GaN}$ powders sample synthesized at $875^{\circ} \mathrm{C}$ was fitted only with two Gaussians and the peaks were located at $360 \mathrm{~nm}$ (3.444 eV), $445 \mathrm{~nm}(2.787 \mathrm{eV})$, as shown in the Fig. 4c. The recombination radiation between the shallow donor levels and the valence band will have a red shift and broaden because of the high oxygen content of sample at $875{ }^{\circ} \mathrm{C}$ and below [6], then merge with the peak relating to defect levels.

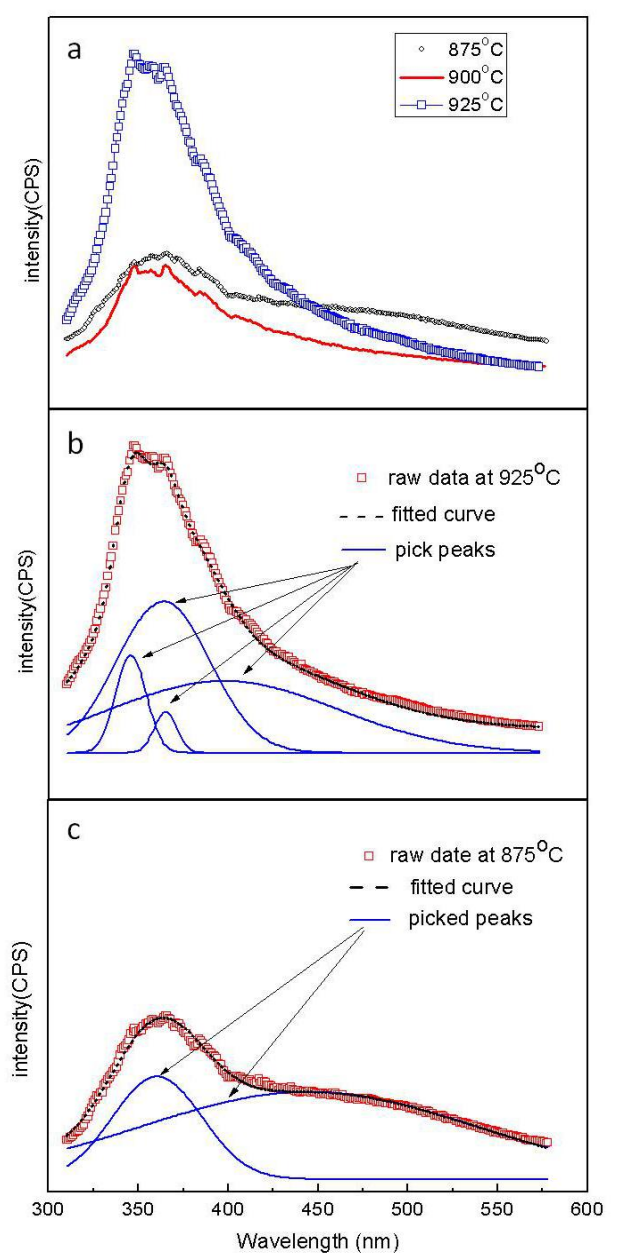

Fig. 4. Room-temperature PL spectra (a) of the powders at $925^{\circ} \mathrm{C}$ (blue square symbols line), $900^{\circ} \mathrm{C}$ (red solid line), and $875^{\circ} \mathrm{C}$ (black circle symbols), fitted curve graphs of the powders at $925^{\circ} \mathrm{C}(\mathrm{b})$, and

\section{Conclusions}

In summary, GaN powders with hexagonal wurtzite structure are synthesized using a simple and economical method that gallium oxide is nitrided under flow of ammonia at quartz tube furnace. From the XRD and TEM result the present GaN powders have clear 
preferred orientation of $<002>$. The similar shape and size of $\mathrm{Ga}_{2} \mathrm{O}_{3}$ and $\mathrm{GaN}$ provide explanation to the growth mechanism of the $\mathrm{GaN}$, i.e. the conversion of gallium oxide to $\mathrm{GaN}$ don't go through the gaseous species of $\mathrm{Ga}_{2} \mathrm{O}$ but solid-state gallium oxynitrides $\left(\mathrm{GaO}_{\mathrm{x}} \mathrm{N}_{\mathrm{y}}\right)$ as intermediates, and that is the very reason of preferred orientation. The PL spectra show that the near band edge emission of the present $\mathrm{GaN}$ is $346 \mathrm{~nm}(3.584 \mathrm{eV})$ at room temperature, which exhibits an obvious blue shift of $19 \mathrm{~nm}(187 \mathrm{meV})$ because of a decrease in disorder of the material that is decided by the (002) plane preferred orientation. It accounts for the GaN powder with preferred orientation prepared in this method can be used as UV luminescence material.

This research was supported by the Natural Science Foundation of China (No. 51302250), the cutting-edge technology research and development program of Zhengzhou Science and Technology Bureau (No.141PQYJS552), and the Internal Research Fund of Zhengzhou University of light industry (No.2013XJJ010).

\section{References}

1. C. B. Han, C. He, X. J. Li, Adv. Mater., 23 4811-4814 (2011)

2. W. J. Jung, Mater. Lett., 60 2954-2957 (2006)

3. W. Z. Zhong, H. S. Luo, S. K. Hua, G. S. Xu, J. Synth. Cryst., 33(4) 475-478 (2004)

4. Z. Y. Zhao, X. G. Li, S. R. Wang, Y. Xiao, J. Synth. Cryst., 43(7) 1611-1619 (2014)

5. R. Garcia., G. A. Hirata, A. C. Thomas, F. A. Ponce, Opt. Mater., 29 19-23 (2006)

6. H. S. Guder, B Abay ., H. Efeoglu, Y. K. Yogurtcu, Bulg. J. Phys., 27(2) 72-75 (2000) 